\title{
Mathematical Models for Planning Vegetative Propagation under Controlled Environments
}

\author{
Chieri Kubota ${ }^{1}$ and Toyoki Kozai ${ }^{2}$ \\ Department of Bioproduction Science, Faculty of Horticulture, \\ Chiba University, Matsudo, Chiba 271-8510, Japan
}

The use of high quality transplants is crucial to achieve high yield and quality of the final products. During recent decades, production of transplants has been separated from final crop production. Many growers purchase quality transplants produced at remote locations. This organizational separation of transplant and final crop productions has contributed to the development and subsequent standardization of methods and techniques for producing transplants.

Demand for high quality, genetically uniform transplants is expected to increase in the 21 st century. Techniques and methods for producing such transplants efficiently need to be developed (Kozai, 1998). Research directed toward transplant production using artificial lighting systems under controlled environments was initiated in the late 1980s. Dreesen and Langhans $(1991,1992)$ emphasized the potential benefits of using such systems because transplants have a high value per unit of production area and a short production time. However, the techniques have not been adopted by commercial growers because of a general lack of knowledge as to how to apply them on a commercial scale. Economic analysis (i.e., use of energy and resources per transplant produced) and development of specific technologies are needed for efficient production.

Vegetative propagation has been a significant mode of transplant production (Hartmann et al., 1997), and the number of species propagated vegetatively has been increasing in commercial transplant production operations. Propagation often begins with in vitro micropropagation (vegetative propagation using micropropagules) for establishing virus-free or pathogen-free stock plants, followed by propagation ex vitro (macro-propagation). The number of plantlets propagated in vitro is usually minimized to reduce production cost. Such plantlets are transferred to sterile soil or to hydroponic systems in an arthropod-excluding screen house and grown as stock plants for increasing pathogen-free propagules and transplants.

One of the advantages of vegetative propagation under artificial lighting conditions is that

\footnotetext{
Received for publication on 25 Oct. 1999. Accepted for publication 18 Apr. 2000. Mention of trademark, proprietary product, or vendor does not constitute a guarantee or warranty of the product and does not imply its approval to the exclusion of other products or vendors that also may be suitable. The cost of publishing this paper was defrayed in part by the payment of page charges. Under postal regulations, this paper therefore must be hereby marked advertisement solely to indicate this fact.

${ }^{1}$ Associate Professor. E-mail address: ckubota@ midori.h.chiba-u.ac.jp

${ }^{2}$ Professor.
}

rates of plant growth and multiplication can be precisely controlled, and therefore those rates in each propagation cycle can be predicted by using a model. However, accuracy of predicting the number of transplants produced after many repetitions of a propagation cycle decreases (because of underestimation or overestimation), since a small difference in the multiplication rate in each cycle will create a large difference in the number of transplants produced after many cycles. Transplant production often targets narrow market demands, and unpredictability tends to cause significant overproduction in the off-peak times or underproduction in the peak times. The number of standardized transplants with acceptable quality must meet the scheduled demand if savings in production costs, energy, and resources are to be realized. Therefore, development of strategic planning methods capable of precise prediction of production may lead to more optimal propagation processes.

Modeling and simulation are needed for optimizing transplant production by scheduling production and predicting the number of transplants produced. Since vegetative propagation tends to be more complicated than seedling production, modeling techniques might significantly improve the process. Unlike models for plant growth, models for vegetative propagation have not been well investigated. Among limited literature, Simonton and Thai (1988) developed models for planning micropropagation, and successfully demonstrated optimization of propagation to meet demand. Walker (1995) developed a linear model for maximizing profit in production of tissue-cultured plants.

Modeling and simulation for optimization of propagation should be further studied with consideration of the environmental and biological conditions that affect plant growth and development. Our objectives were: 1) to develop generic models that can be modified and used, along with peripheral models, for simulating the number of propagules for transplant production planning and environmental control; and 2) to simulate the effects of environmental factors, such as air temperature, $\mathrm{CO}_{2}$ concentration, and photosynthetic photon flux $(P P F)$ on the number of propagules produced.

\section{VEGETATIVE PROPAGATION AND MODEL STRUCTURES}

\section{Definitions and rule description of} vegetative propagation

Initial efforts focused on the development of generic multiplication models applicable for a variety of vegetative propagation meth- ods. Fig. 1 shows an example of vegetative propagation starting with a single-node cutting with one leaf. The propagation process is sometimes followed by a transplant finishing process (rooting or hardening stage) before shipping (not shown in Fig. 1). The following propagation definitions and statements will be used. They are applicable to most vegetative propagation systems, including micropropagation and macro-propagation for transplant production.

1) Propagules are plant tissues or organs that can be used as starting materials for propagation (propagule production).

2) Stock plants are plants grown in order to produce propagules. Their status (stage) of maturity, whether ready to be harvested or not, is irrelevant to the definition of stock plants. Even cuttings that have just been planted in the propagation system can be referred to as stock plants.

3) Propagation cycle $\left(\mathrm{T}_{\mathrm{c}}\right)$ is the duration of time required for stock plants to grow and produce new propagules.

4) Since multiplication rates are class-dependent and more than one class (kind) of propagule can be used for propagation, propagules are often classified, e.g., as cutting and stock plant base [the base of the stock plant remaining after harvesting the cuttings, (Fig. 1)].

5) Propagules are further classified according to their attributes (age, size, etc.). Stock plants are classified with attributes such as days in $\mathrm{T}_{c}$, along with the attributes of their original propagules.

6) A portion of the propagules can leave the propagation process by being either sold or transferred to the finishing stage. The rest of the harvested propagules are used for serial propagation.

7) A portion of the propagules or stock plants can be stored for growth suppression and quality preservation.

8) Propagation processing has spatial restrictions, such as areas for propagation, finishing and storage.

9) The number of propagules handled per unit time can be limited by labor availability.

Statements 7), 8) and 9) are not considered in the preliminary models described below.

\section{Mathematical Description}

Considering the ecological characteristics of vegetative propagation in a closed environment, where plants repeat their "life cycles" from propagules, continue growth as stock plants, and finally produce new propagules, a demographic approach often 


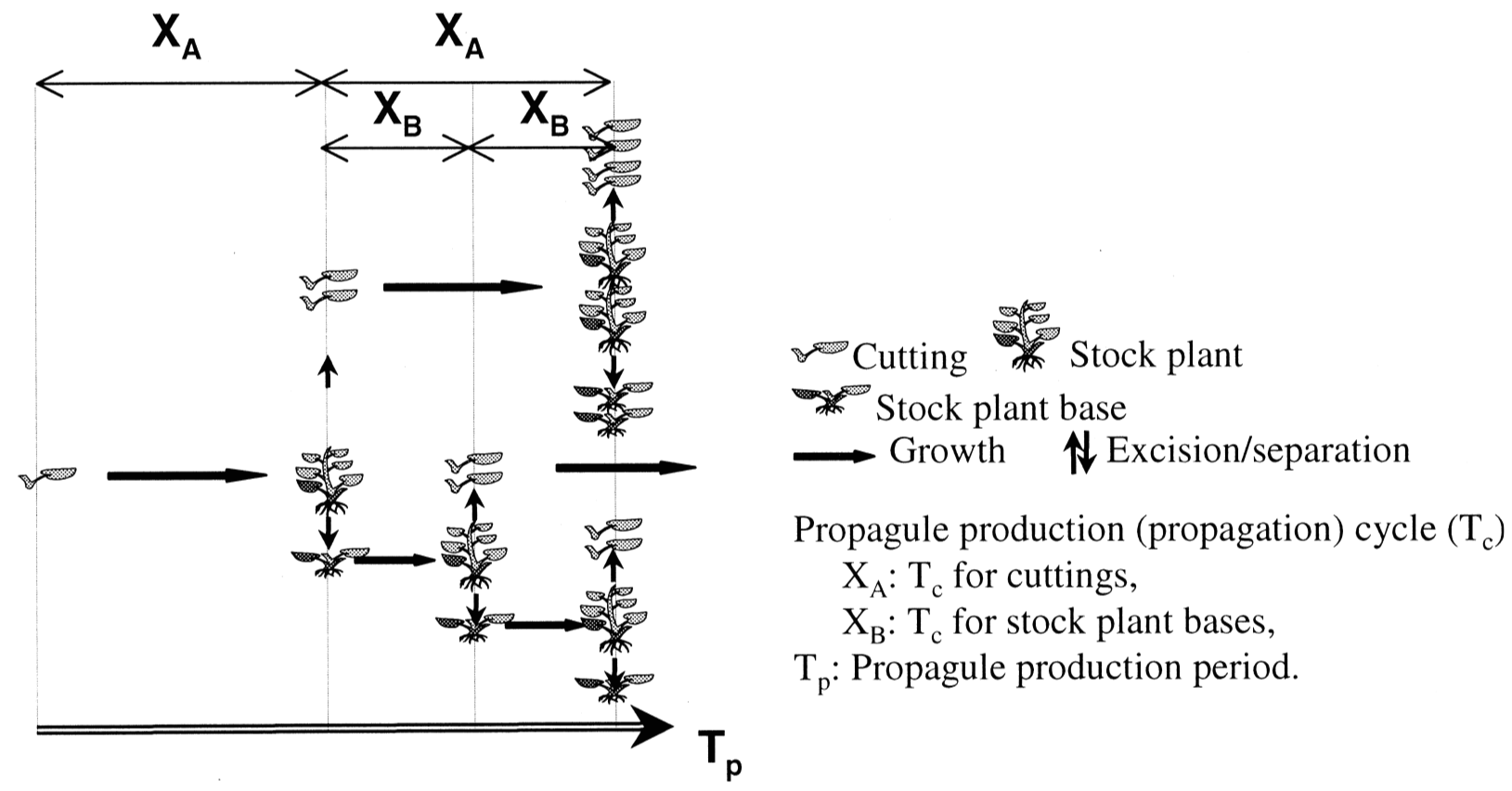

Fig. 1. An example of sweetpotato propagule production when both cuttings and stock plant bases are used as propagules. Cuttings are grown for $\mathrm{X}_{\mathrm{A}} \mathrm{d}$ and produce more cuttings. The remaining stock plant bases are reused and grown for $\mathrm{X}_{\mathrm{B}} \mathrm{d}$ for producing cuttings.

used in ecological population dynamics can be applied. As an extension to the Leslie matrix (1945), Law (1983) introduced a transition matrix model in ecological plant population dynamics. Such matrices can be applied in vegetative propagation systems, since such propagation can be expressed as a transition from propagules to stock plants and from stock plants to propagules. For developing transition matrix models, the observation interval of the transition is determined. The interval will be shorter (daily or weekly transition) in vegetative propagation than in ecological population dynamics (seasonal or annual transition). Another differing characteristic of transition matrix models for vegetative propagation is that the models can be deterministic and coefficients can be manipulated according to the production strategy (decision of a production manager), while those in the ecological transition are stochastic.

The dynamics of the number of propagules and stock plants are expressed in a simple matrix notation as a transition with daily interval:

$$
\mathbf{N}(\mathrm{t}+1)=\mathbf{M} \cdot \mathbf{N}(\mathrm{t})
$$

where $\mathbf{N}(\mathrm{t})$ and $\mathbf{N}(\mathrm{t}+1)$ are the population vectors (single column matrices) showing the number of each population constituent on days $t$ and $t+1$, respectively. The multiplication matrix (M) contains all the multiplication and transition parameters identical for each population constituent. The observation interval is daily, but observations are made at the end of the day. Therefore, all the numbers shown in the population vectors are those after the scheduled operations (cutting, transferring, etc.) of that day.
According to the propagation rules described above, we will see some or all of the following three population constituents in the propagation system on a given day t: 1) harvested propagules; 2) stock plants grown for successive propagule production in the propagation system; and 3) propagules leaving the propagation system (for shipping or transition to the finishing stage). The population vector on day t is now expressed with three subvectors:

$$
\mathbf{N}(\mathrm{t})=[\mathbf{P}(\mathrm{t}) ; \mathbf{S}(\mathrm{t}) ; \mathbf{F}(\mathrm{t})]
$$

where $\mathbf{P}(\mathrm{t}), \mathbf{S}(\mathrm{t})$, and $\mathbf{F}(\mathrm{t})$ consist of the numbers of harvested propagules, stock plants, and propagules leaving the system, respectively, on day t. They are further classified as follows:

$$
\begin{gathered}
\mathbf{P}(\mathrm{t})=\left[\mathrm{P}_{\mathrm{A}}(\mathrm{t}) ; \mathrm{P}_{\mathrm{B}}(\mathrm{t}) ; \ldots .\right] \\
\mathbf{S}(\mathrm{t})=\left[\mathrm{S}_{\mathrm{A} 0}(\mathrm{t}) ; \mathrm{S}_{\mathrm{A} 1}(\mathrm{t}) ; \mathrm{S}_{\mathrm{A} 2}(\mathrm{t}) ; \ldots ;\right. \\
\left.\mathrm{S}_{\mathrm{AX}_{\mathrm{A}}-1}(\mathrm{t}) ; \mathrm{S}_{\mathrm{B} 0}(\mathrm{t}) ; \mathrm{S}_{\mathrm{B} 1}(\mathrm{t}) ; \ldots ; \mathrm{S}_{\mathrm{BX}_{\mathrm{B}}-1}(\mathrm{t}) ;\right] \\
\mathbf{F}(\mathrm{t})=\left[\mathrm{F}_{\mathrm{A}}(\mathrm{t}) ; \mathrm{F}_{\mathrm{B}}(\mathrm{t}) ; \ldots\right]
\end{gathered}
$$

where $\mathrm{P}_{\mathrm{A}}(\mathrm{t}), \mathrm{P}_{\mathrm{B}}(\mathrm{t}), \ldots$ and $\mathrm{F}_{\mathrm{A}}(\mathrm{t}), \mathrm{F}_{\mathrm{B}}(\mathrm{t}), \ldots$ are numbers of harvested $(\mathrm{P})$ and leaving $(\mathrm{F})$ propagules classified into $\mathrm{A}, \mathrm{B}, \ldots$, respectively, with different attributes. $\mathrm{S}_{\mathrm{Ax}}(\mathrm{t}), \mathrm{S}_{\mathrm{Bx}}(\mathrm{t})$, $\ldots(\mathrm{x}=0,1,2, \ldots)$ are the numbers of stock plants originating from propagules classified as $A, B, \ldots$ and grown for $\mathrm{x} \mathrm{d}\left[\mathrm{x}<\mathrm{X}_{\mathrm{A}}\right.$ for $\mathrm{S}_{\mathrm{Ax}}(\mathrm{t})$; $\mathrm{x}<\mathrm{X}_{\mathrm{B}}$ for $\left.\mathrm{S}_{\mathrm{Bx}}(\mathrm{t}) ; \ldots\right]$ in $\mathrm{T}_{\mathrm{c}}$. According to the propagation rules, the number of each population constituent on day $t+1$ can be written as follows:

$$
\left.\begin{array}{l}
\mathbf{P}(t+1)=\mathbf{M}_{S \mathbf{P}} \cdot \mathbf{S}(\mathrm{t}) \\
\mathbf{S}(\mathrm{t}+1)=\mathbf{M}_{\mathbf{P S}} \cdot \mathbf{P}(\mathrm{t})+\mathbf{M}_{\mathrm{SS}} \cdot \mathbf{S}(\mathrm{t}) \\
\mathbf{F}(\mathrm{t}+1)=\mathbf{M}_{\mathbf{S F}} \cdot \mathbf{S}(\mathrm{t})
\end{array}\right\}
$$

where $\mathbf{M}_{\mathrm{SP}}, \mathbf{M}_{\mathrm{PS}}$, and $\mathbf{M}_{\mathrm{ss}}$ are the multiplication and transition submatrices, consisting of multiplication and transition parameters from stock plants on day $t$ to propagules on day $t+1$, from propagules on day t to stock plants on day $\mathrm{t}+1$, and from stock plants on day $\mathrm{t}$ to stock plants on day $\mathrm{t}+1$, respectively. $\mathbf{M}_{\mathbf{S F}}$ is the submatrix, including parameters responsible for the decision regarding the ratios of the number of propagules leaving the system over that of harvested propagules from stock plants. Parameters contained in the multiplication submatrices $\mathbf{M}_{\mathrm{SP}}$ and $\mathbf{M}_{\mathrm{SS}}$ can be expressed as functions, including variables reflecting environmental conditions, such as air temperature, $P P F$, and $\mathrm{CO}_{2}$ concentration. The Eq. [6] are re-written in matrix notation as in Eq. [7].

$$
\left[\begin{array}{l}
\mathbf{P}(\mathrm{t}+1) \\
\mathbf{S}(\mathrm{t}+1) \\
\mathbf{F}(\mathrm{t}+1)
\end{array}\right]=\left[\begin{array}{ccc}
0 & \mathbf{M}_{\mathbf{S P}} & 0 \\
\mathbf{M}_{\mathbf{P S}} & \mathbf{M}_{\mathbf{S S}} & 0 \\
0 & \mathbf{M}_{\mathbf{S F}} & 0
\end{array}\right]\left[\begin{array}{l}
\mathbf{P}(\mathrm{t}) \\
\mathbf{S}(\mathrm{t}) \\
\mathbf{F}(\mathrm{t})
\end{array}\right]
$$

Using Eqs. [2], [3], [4], [5], and [7], we can simulate the number of each population constituent and its dynamics. Once the propagation process is quantitatively understood, several important variables can be derived for considering propagation efficiency. For example, the total number of stock plants currently present in the production area TTL $(\mathrm{t})$ is derived as:

$\operatorname{TTL}(\mathrm{t})=\boldsymbol{S}_{\mathbf{S}}(\mathrm{t})=\sum_{\mathrm{x}=0}^{\mathrm{X}_{\mathrm{A}}-1} \mathbf{S}_{\mathbf{A x}}+\sum_{\mathrm{x}=0}^{\mathrm{X}_{\mathrm{B}}-1} \mathbf{S B x}+\ldots$

The TTL $(t)$ is necessary for considering the limitation of capacity in a propagation system. For example, based on $\mathbf{F}(\mathrm{t})$ and TTL $(\mathrm{t})$, a productivity (PRDT, the number of final 
propagules divided by total number of stock plants present in the production area on the previous day) is shown as:

$$
\operatorname{PRDT}(\mathrm{t})=\mathbf{F}(\mathrm{t}) / \mathrm{TTL}(\mathrm{t}-1)
$$

$\operatorname{PRDT}(t)$ is shown as a vector in this equation since $\mathbf{F}(\mathrm{t})$ is a vector. Variables such as TTL $(\mathrm{t})$ and PRDT $(\mathrm{t})$ will be used in analyzing the propagation process, and they will serve important roles in optimizing it.

\section{AN APPLICATION OF THE MODELS TO SWEETPOTATO [IPOMOEA BATATAS (L.)] TRANSPLANT PRODUCTION UNDER CONTROLLED ENVIRONMENTS}

The generic models described above (Eqs. [1] to [9]) were applied, with necessary modifications, to sweetpotato vegetative propagation (cutting production) under a controlled environment. Sweetpotato is an important crop in many Asian and African countries, and will contribute to food, energy, and plastics production in the 21st century (Kozai et al., 1996).

Axillary shoot cuttings with several leaves have been commonly used as propagules in conventional sweetpotato propagation; in most cases, this is carried out in screen houses to prevent stock plants from reinfection with viruses carried by insect vectors. The use of single node, leafy cuttings as propagules has been considered unsuitable because of the low survival and growth rates under environmental conditions of conventional propagation systems. However, it may be suitable under controlled environment with artificial lighting, since environmental conditions can be manipulated to achieve a high percentage of survival of single-node cuttings and high growth/development rates of the new axillary shoots. Furthermore, simulation has shown that more transplants can be obtained during a given propagation period $\left(\mathrm{T}_{\mathrm{p}}\right)$ when single-node, rather than multi-node, cuttings are used as propagules (unpublished data). In the present study, single node, leafy cuttings were used as propagules. Each stock plant had several leaves on its single axillary shoot, and was divided at the end of the propagation cycle into single node cuttings, each with one leaf.

\section{Number of propagules obtained in a propagation cycle}

Axillary shoot development from a singlenode cutting is largely controlled by environmental conditions. Thus, leaf development rates, expressed as functions of environmental factors, primarily determine the number of propagules obtained per stock plant. Such rates should take into account the number of leaves usable as propagules. Preliminary experiments have shown that the number of sweetpotato single-node cuttings produced per stock plant $\left[\mathrm{P}_{\mathrm{CS}}(\mathrm{t})\right]$ increases linearly after a lag time:

$$
\mathrm{P}_{\mathrm{CS}}(\mathrm{t})=1+\left(\mathrm{t}-\mathrm{t}_{0}\right) / \mathrm{t}_{\mathrm{p}}
$$

where $t$ is days after planting the propagules, $\mathrm{t}_{0}$ is days to produce the first leaf usable as a propagule, and $t_{p}$ is the constant interval in days between production of two successive leaves usable as propagules. The $t_{0}$ and $t_{p}$ values can be expressed as functions of environmental variables. A constant interval between emergence of two successive leaves larger than a standard leaf has been defined as a plastochron (Erickson and Michelini, 1957). In the present study, leaves larger than the initial leaf of the original propagules were considered to be usable as propagules.

\section{Model descriptions for propagule production}

Another class of propagule (other than cuttings) that is often used in sweetpotato propagation is stock plant bases (basal, rooted part of the stock plants left after removal of the axillary shoots). After cuttings have been harvested, stock plant bases, with or without their lowest, newly developed leaves, may be retained in propagation for regenerating new axillary shoots. Such bases are generally considered to have higher multiplication rates than cuttings, and their propagation cycle can therefore be shorter. The same bases can be repeatedly used to produce cuttings. They will be discarded after a maximum number of repetitions $(\mathrm{K}, \mathrm{K}=1,2,3 \ldots)$. Thus the population vector for sweetpotato propagation considers two classes of propagules and two classes of stock plants originating from either propagule class, as in Eq. [11]:

$\mathbf{N}(\mathrm{t})=\left[\mathbf{P}_{\mathbf{C}}(\mathrm{t}) ; \mathbf{P}_{\mathbf{B}}(\mathrm{t}) ; \mathrm{D}_{\mathrm{B}}(\mathrm{t}) ; \mathbf{S}_{\mathrm{C}}(\mathrm{t}) ; \mathbf{S}_{\mathbf{B}}(\mathrm{t}) ; \mathbf{F}_{\mathbf{C}}(\mathrm{t})\right]$

where $\mathbf{P}_{\mathrm{C}}(\mathrm{t}), \mathbf{P}_{\mathrm{B}}(\mathrm{t})$, and $\mathbf{F}_{\mathrm{C}}(\mathrm{t})$ are subvectors containing numbers of single-node cuttings, stock plant bases, and final single-node cuttings (those leaving the propagation system) on day $t$, respectively, each classified with a set of attributes (age, size, etc.). $D_{B}(t)$ is the number of discarded stock plant bases on day t. $\mathbf{S}_{\mathrm{C}}(\mathrm{t})$ and $\mathbf{S}_{\mathbf{B}}(\mathrm{t})$ are subvectors containing numbers of stock plants originating from single-node cuttings and stock plant bases, respectively, and continue in the propagation system. Optimum duration of $\mathrm{T}_{\mathrm{c}}$ and maximum number of repetitions $(\mathrm{K})$ for using the same stock plant bases could be determined through optimization of the production process

The $\mathbf{N}(t+1)$ is given by multiplication of a square matrix $\mathbf{M}$ and $\mathbf{N}(\mathrm{t})$ as shown in Eq. [1]. The multiplication matrix $\mathbf{M}$ for sweetpotato propagation is written as:

$$
\mathbf{M}=\left[\begin{array}{cccccc}
0 & 0 & 0 & \mathbf{M}_{\mathbf{S c C}} & \mathbf{M}_{\mathbf{S b C}} & 0 \\
0 & 0 & 0 & \mathbf{M}_{\mathbf{S c B}} & \mathbf{M}_{\mathbf{S b B}} & 0 \\
0 & 0 & 0 & 0 & \mathbf{M}_{\mathbf{S b D}} & 0 \\
\mathbf{M}_{\mathbf{C S c}} & 0 & 0 & \mathbf{M}_{\mathbf{S c S c}} & \mathbf{M}_{\mathbf{S b S c}} & 0 \\
0 & 0 & 0 & \mathbf{M}_{\mathbf{S c S b}} & \mathbf{M}_{\mathrm{SbSb}} & 0 \\
0 & 0 & 0 & \mathbf{M}_{\mathbf{S c F}} & \mathbf{M}_{\mathbf{S b F}} & 0
\end{array}\right]
$$

where $\mathbf{M}_{\mathrm{ScC}}, \mathbf{M}_{\mathrm{SbC}}, \mathbf{M}_{\mathrm{ScB}}, \mathbf{M}_{\mathrm{SbB}}, \mathbf{M}_{\mathrm{SbD}}, \mathbf{M}_{\mathrm{CSc}}$, $\mathbf{M}_{\mathrm{ScS}}, \mathbf{M}_{\mathrm{SbSc}}, \mathbf{M}_{\mathrm{ScSb}}, \mathbf{M}_{\mathrm{Sb} b}, \mathbf{M}_{\mathrm{ScF}}$, and $\mathbf{M}_{\mathrm{SbF}}$ are multiplication submatrices containing multiplication and transition parameters from one population constituent to another in the population vector. Subscript letters represent stock plants originating from cuttings $\left(\mathrm{S}_{\mathrm{c}}\right)$ or stock plant bases $\left(\mathrm{S}_{\mathrm{b}}\right)$, cuttings $(\mathrm{C})$, stock plant bases (B), discarded stock plant bases (D), and finished cuttings leaving the system $(\mathrm{F})$. The order of the letters indicates the direction of transition from day $t$ to day $t+1$; for example, $\mathbf{M}_{\mathrm{ScC}}$ is the multiplication matrix from a stock plant originating from cuttings on day $t$ to cuttings on day $\mathrm{t}+1$.

\section{Simulation of propagation}

The models and parameters were incorporated, and simulations were conducted using MATLAB (Ver. 5.2, The Math Works, Natick, Mass.) run on a personal computer. To simplify the results, constraints of production were not considered in the present simulations. All the cuttings were considered to have identical multiplication rates, as were stock plant bases within their $\mathrm{K}$ value limit. Thus, $\mathrm{P}_{\mathrm{C}}(\mathrm{t})$ and $\mathrm{F}_{\mathrm{C}}(\mathrm{t})$ were considered as numbers (not as vectors), $\mathbf{S}_{\mathrm{C}}(\mathrm{t})$ had an attribute of days in $\mathrm{T}_{\mathrm{c}}, \mathbf{P}_{\mathbf{B}}(\mathrm{t})$ had $\mathrm{K}$ value, and $\mathbf{S}_{\mathbf{B}}(\mathrm{t})$ had attributes of $T_{c}$ and $K$ in the present simulations. The simulations were based on the following two scenarios for examining the effects of a ratio of $\mathrm{F}_{\mathrm{C}}(\mathrm{t})$ and $\mathrm{P}_{\mathrm{C}}(\mathrm{t})[\alpha(\mathrm{t})=$ $\left.\mathrm{F}_{\mathrm{C}}(\mathrm{t}) / \mathrm{P}_{\mathrm{C}}(\mathrm{t})\right]$, environmental conditions, and propagation methods (propagation with or without stock plant bases as propagules in addition to cuttings).

Simulation of numbers of population constituents of vegetative propagation as affected by $\alpha(t)$ values (Scenario \#1). Both cuttings and stock plant bases were used as propagules. Each stock plant derived from a cutting and a stock plant base produced five cuttings and one stock plant base after 20 and $12 \mathrm{~d}$, respectively, in one environment (details of the environmental conditions are not defined for this simulation). The $\mathrm{K}$ value of a stock plant base was fixed as $\mathrm{K}=3$. The ratio of number of cuttings leaving the system to that of cuttings harvested on day $\mathrm{t}[\alpha(\mathrm{t}): 0 \leq$ $\alpha \leq 1]$ was varied. The $\alpha(t)$ could be manipulated dynamically but it was considered to have a constant value for the $\mathrm{T}_{\mathrm{p}}$ examined $[\alpha(\mathrm{t})=0.05,0.2,0.5$, and $0.95,0 \leq \mathrm{t} \leq 100]$. Propagation started with 500 cuttings that were planted in transplant trays on day 0 .

Fig. 2 shows the four variables, $\mathrm{P}_{\mathrm{C}}(\mathrm{t})$, $\mathrm{F}_{\mathrm{C}}(\mathrm{t}), \mathrm{D}_{\mathrm{B}}(\mathrm{t})$ and TTL $(\mathrm{t})$, simulated for $0 \leq \mathrm{t} \leq$ 100 at $\alpha(\mathrm{t})=0.05,0.2,0.5$, and 0.95. As was observed in real propagation operations (and therefore, as was expected), smaller $\alpha(\mathrm{t})$ gave greater values in $\mathrm{P}_{\mathrm{C}}(\mathrm{t})$ and TTL $(\mathrm{t})$. At $\alpha(\mathrm{t})=$ 0.95 , the maximum values of TTL $(t), P_{C}(t)$ and $\mathrm{S}(\mathrm{t})$ seemed stable, regardless of the discrete variations. The discrete distribution of production was the result of the different $\mathrm{T}_{c}$ for two classes of propagules. The integrated $\mathrm{F}_{\mathrm{C}}(\mathrm{t})$ for $1 \leq \mathrm{t} \leq 100$ (integrated number of the cuttings that left the propagation system for $100 \mathrm{~d}$ ) at $\alpha(\mathrm{t})=0.05$ was $1.96 \times 10^{5}, 9.1$ times as great as that at $\alpha(\mathrm{t})=0.95(2.16 \times$ $\left.10^{4}\right)$. The TTL $(\mathrm{t})$ remained greater than $\mathrm{F}_{\mathrm{C}}(\mathrm{t})$ 

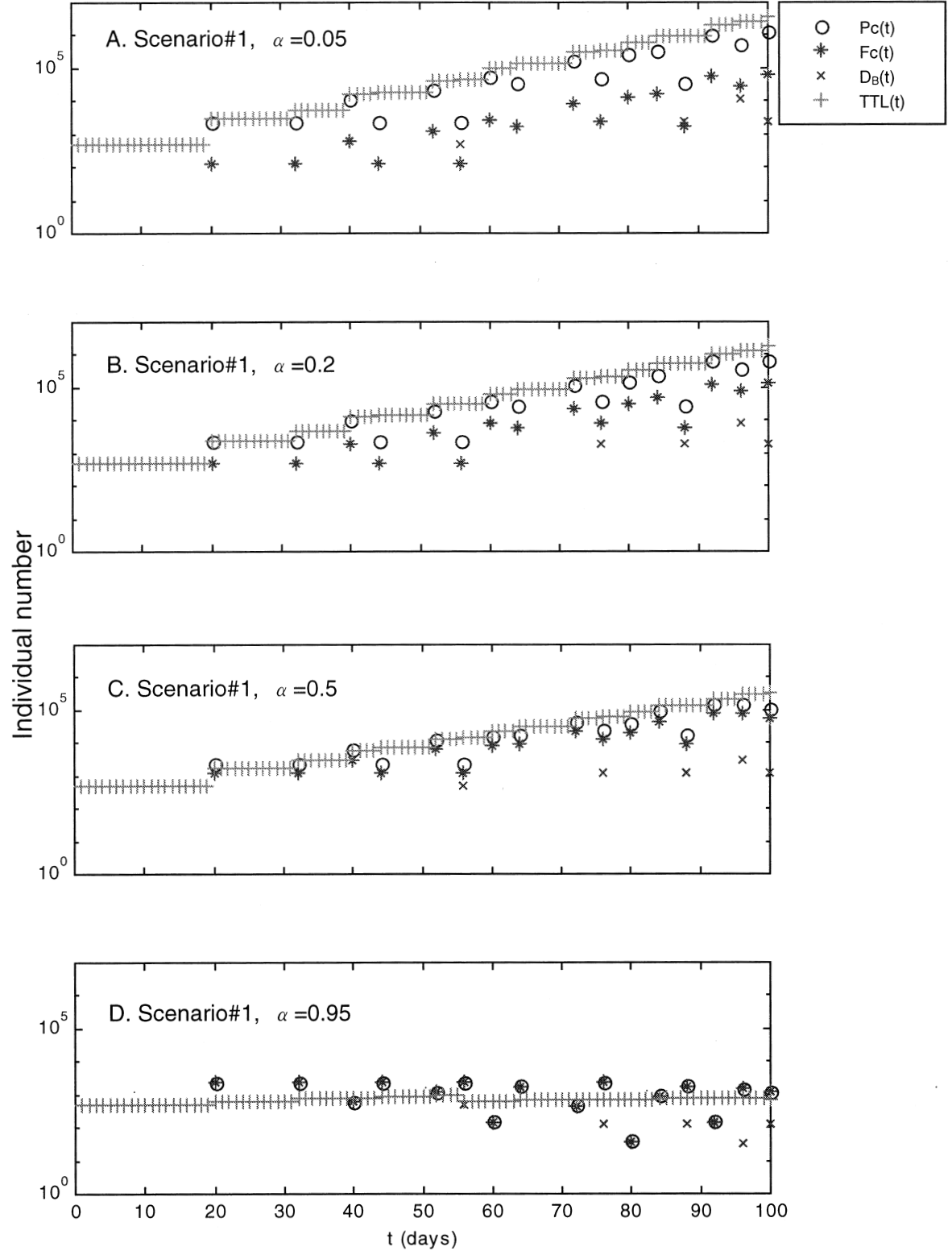

Fig. 2. Simulated numbers of harvested sweetpotato cuttings $\left(\mathrm{P}_{\mathrm{C}}\right)$, cuttings leaving the system $\left(\mathrm{F}_{\mathrm{C}}\right)$, stock plant bases to be discarded $\left(\mathrm{D}_{\mathrm{B}}\right)$ and total stock plants in the propagation area (TTL) with different $\alpha(t)$ values (ratio of number of cuttings to leave the system to that of cuttings harvested on day $t$. $\alpha(\mathrm{t})=0.05,0.2,0.5$, or $0.95,0 \leq \mathrm{t} \leq 100$ ). (Simulation in Scenario \#1).

at $\alpha(\mathrm{t})=0.5$ or lower, while the TTL $(\mathrm{t})$ was mostly lower than $\mathrm{F}_{\mathrm{C}}(\mathrm{t})$ at $\alpha(\mathrm{t})=0.95$, reflecting the increase in the PRDT $(\mathrm{t})$ with increasing $\alpha(\mathrm{t})$ values. For commercial propagation, the TTL $(\mathrm{t})$ should be constant within a certain range satisfying spatial limit. The $\mathrm{F}_{\mathrm{C}}(\mathrm{t})$ should be high enough to meet the market demands, and ideally should be constant. The present simulation suggested that propagation should start with a low $\alpha(\mathrm{t})$ value to increase the number of propagules rapidly. The $\alpha(\mathrm{t})$ value can be increased after TTL $(t)$ or $P_{C}(t)$ has reached ideal ranges, which will be determined through optimization processes. The ideal $\alpha(\mathrm{t})$ values depend on multiplication parameters and propagation cycles of different propagules. Simulation is, therefore, the useful way of finding such values and subsequently for optimizing the propagation pro- cess. Strategic introduction of short-term storage of stock plants or propagules would also contribute to optimizing the propagation process. Storage has not been considered in the present models.

Simulation of numbers of population constituents of sweetpotato vegetative propagation as affected by use of stock plant bases as propagules under different environmental conditions (Scenario \#2). Propagation with cuttings as propagules was compared with that with both cuttings and stock plant bases as propagules ( $\mathrm{K}=3$ for stock plant bases). Stock plants derived from cuttings and stock plant bases were grown for 20 and $12 \mathrm{~d}$, respectively. The $\alpha(\mathrm{t})$ was fixed at $\alpha(\mathrm{t})=0.8$ $(0 \leq \mathrm{t} \leq 100)$. Two sets of environmental conditions were considered: 1) high $P P F$ $\left(300 \mu \mathrm{mol} \cdot \mathrm{m}^{-2} \cdot \mathrm{s}^{-1}\right)$, high $\mathrm{CO}_{2}$ concentration
(1000 $\mu \mathrm{mol} \cdot \mathrm{mol}^{-1}$ ), and high temperature $\left(30^{\circ} \mathrm{C}\right)$; vs. 2) low $P P F\left(150 \mu \mathrm{mol} \cdot \mathrm{m}^{-2} \cdot \mathrm{s}^{-1}\right)$, low $\mathrm{CO}_{2}$ concentration $\left(350 \mu \mathrm{mol} \cdot \mathrm{mol}^{-1}\right)$, and low temperature $\left(25^{\circ} \mathrm{C}\right)$. Propagation started with 500 cuttings that were planted on day 0 .

A separately conducted experiment provided the parameters $t_{0}$ and $t_{p}$ in Eq. [10] as 4 and 1.3 , respectively, under high PPF, high $\mathrm{CO}_{2}$ concentration, and high temperature (HIGH) conditions, and as 8 and 2.0, respectively, under low $P P F$, low $\mathrm{CO}_{2}$ concentration, and low temperature (LOW) conditions (the experimental details will be provided in a separate report). Thus, the numbers of cuttings produced per stock plant in $20 \mathrm{~d}$ are 13 for the HIGH conditions and 7 for the LOW conditions. Stock plant bases were considered to produce the same number of cuttings per propagation cycle as did cuttings, but with a shorter propagation cycle (12d). Those numbers were included in the model as parameters in submatrices $\mathbf{M}_{\mathbf{S c C}}$ and $\mathbf{M}_{\mathbf{S b C}}$ in Eq. [12].

Fig. 3 shows the four variables, $P_{C}(t)$, $F_{C}(t), D_{B}(t)$ and TTL $(t)$, simulated for $0 \leq t \leq$ 100 with or without usage of stock plant bases as propagules in addition to cuttings under two environmental conditions. Production of cuttings occurred every $20 \mathrm{~d}$ when only cuttings were used as propagules, while it had a discrete variation when stock plant bases were used in addition to cuttings. The use of stock plant bases as propagules increased the $P_{C}(t), F_{C}(t)$ and TTL $(t)$. The integrated $F_{C}(t)$ for $100 d(1 \leq t \leq 100)$ when both cuttings and stock plant bases were used as propagules were $3.06 \times 10^{5}$ and $1.62 \times 10^{6}$ under LOW and HIGH conditions, respectively, and 7.5 and 4.2 times as great as that when only cuttings were used as propagules under the same environmental conditions. Aitken-Christie and Jones (1987) developed a new propagation method for Pinus radiata D. Don shoots in vitro, and reported that maintaining 'shoot hedge' (shoot clumps maintained like mini-hedges in the same vessel for multiple production of shoots) in vitro contributed to rapid production of shoots. The simulated results in the present study generally agree with that observation in terms of enhanced production by using shoot hedges (or stock plant bases) as propagules.

The integrated $D_{B}(t)$ for $100 \mathrm{~d}$ when both cuttings and stock plant bases were used as propagules was smaller $\left(5.47 \times 10^{3}\right.$ and $3.68 \times$ $10^{4}$ with cuttings vs. $3.58 \times 10^{3}$ and $7.78 \times 10^{3}$ with cuttings and stock plant bases under LOW and HIGH conditions, respectively), and thus the ratio of integrated $D_{B}(t)$ to integrated $F_{C}(t)$ was smaller, than when only cuttings were used as propagules under the same environmental conditions. Those values should be small for minimizing waste of plant material. Reducing the percentage of plants that are propagated and later discarded is important for efficient operation of commercial nurseries (Hartmann et al., 1997). The present simulation suggested that use of stock plant bases in addition to cuttings saved energy and resources for growing stock plants by reducing plant waste. However, the PRDT(t) was smaller 

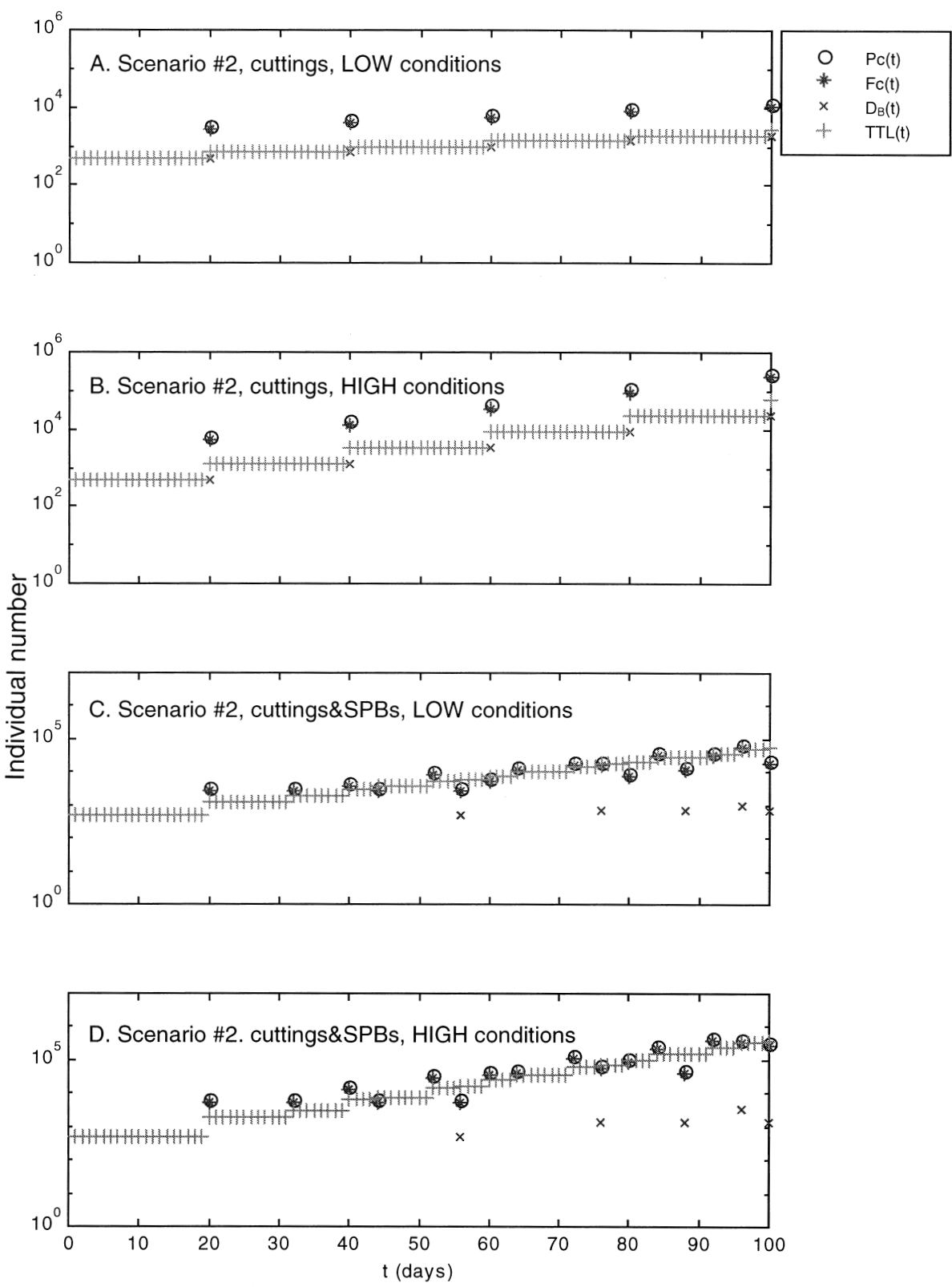

Fig. 3. Simulated numbers of harvested sweetpotato cuttings $\left(\mathrm{P}_{\mathrm{C}}\right)$, cuttings leaving the system $\left(\mathrm{F}_{\mathrm{C}}\right)$, stock plant bases to be discarded $\left(\mathrm{D}_{\mathrm{B}}\right)$, and total stock plants in the propagation area (TTL) with or without use of stock plant bases (SPBs) in addition to cuttings as propagules under different environmental conditions. LOW conditions: $150 \mu \mathrm{mol} \cdot \mathrm{m}^{-2} \mathrm{~s}^{-1} \mathrm{PPF}, 350 \mu \mathrm{mol} \cdot \mathrm{mol}^{-1} \mathrm{CO}_{2}$ concentration, and $25^{\circ} \mathrm{C}$; HIGH conditions: $300 \mu \mathrm{mol} \cdot \mathrm{m}^{-2} \cdot \mathrm{s}^{-1} P P F, 1000 \mu \mathrm{mol} \cdot \mathrm{mol}^{-1} \mathrm{CO}_{2}$ concentration, and $30^{\circ} \mathrm{C}$. (Simulation in Scenario \#2).

than that for cuttings only. The PRDT $(\mathrm{t})$ were constant for cuttings (5.6 and 10.4 under LOW and HIGH conditions, respectively), while variable for both cuttings and stock plant bases (0.4 to 5.6 and 0.3 to 10.4 under LOW and HIGH conditions, respectively). The PRDT(t) decreased when stock plant bases were used because many stock plants continued in the propagation system.

The HIGH conditions provided 7.1 and 12 times as great an integrated $\mathrm{F}_{\mathrm{C}}(\mathrm{t})$ for $100 \mathrm{~d}$ as did the LOW conditions with and without use propagation method, could optimize the propagation process.

\section{CONCLUSIONS}

The generic models developed in the present study were effective tools for qualitative understanding of transplant production by vegetative propagation. Application of developed models to sweetpotato vegetative propagation has shown that they can be used for propagation planning and environmental control based on simulation and optimization. The simulations successfully predicted the effects of environmental conditions and propagation methods on numbers of each class of propagules and stock plants after many propagation cycles and were effective in analyzing production efficiency. Propagation can be optimized by selecting optimal combinations of production methods and environmental conditions based on simulations. Modified models will be applicable to other types of vegetative propagation and to other transplant production systems as well, including plug seedling production, where various stages of seedling plugs are maintained in production systems.

\section{Literature Cited}

Aitken-Christie, J. and C. Jones. 1987. Towards automation: Radiata pine shoot hedges in vitro. Plant Cell Tiss. Org. Cult. 8:185-196.

Dreesen, D.R. and R.W. Langhans. 1991. Uniformity of impatiens plug seedling growth in controlled environments. J. Amer. Soc. Hort. Sci. 116:786-791

Dreesen, D.R. and R.W. Langhans. 1992. Temperature effects on growth of impatiens plug seedlings in controlled environments. J. Amer. Soc. Hort. Sci. 117:209-215.

Erickson, R.O. and F.J. Michelini. 1957. The plastochron index. Amer. J. Bot. 44:297-305.

Hartmann, H.T., D.E. Kester, F.T. Davies, Jr., and R.L. Geneve. 1997. Plant propagation: Principles and practices. Prentice-Hall, Upper Saddle River, N.J.

Kozai, T. 1998. Transplant production under artificial light in closed systems, p. 296-308. In: H.Y. Lu, J.-M. Sung, and C.H. Kao (eds.). Asian Crop Sci. 1998 (Proc. 3rd Asian Crop Sci. Conf.). Taichung, Taiwan.

Kozai, T., C. Kubota, and Y. Kitaya. 1996. Sweetpotato technology for solving the global issues on food, energy, natural resources, and environment in the 21st century (in Japanese). Environ. Control. In Biol. 34:105-114.

Law, R. 1983. A model for the dynamics of plant population containing individuals classified by age and size. Ecology 64:224-230.

of stock plant bases as propagules, respectively. Note that the impact of the environmental conditions was more pronounced when only cuttings were used as propagules. The HIGH conditions increased the integrated $D_{B}(t)$ for $100 \mathrm{~d}$, but decreased the ratio of integrated $D_{B}(t)$ to integrated $F_{C}(t)$ for $100 \mathrm{~d}$. Values of PRDT $(t)$ were higher under the HIGH than under the LOW conditions, since more cuttings were produced per stock plant. Controlling environment to enhance the multiplication rate, in combination with selecting a proper
Leslie, R.H. 1945. On the use of matrices in certain 212.

Simonton, W. and C.N. Thai. 1988. Plant tissue culture production planning using computer simulation/optimization. Trans. ASAE. 31:1616-1622.

Walker, P.N. 1995. System analysis and engineering, p. 65-85. In: J. Aitken-Christie, T. Kozai and M.A.L. Smith (eds.). Automation and environmental control in plant tissue culture. Kluwer Academic, Dordrecht, The Netherlands population mathematics. Biometrika 33:183- 